\title{
Stromal cell-derived factor-1 $\alpha$ and macrophage migration-inhibitory factor induce metastatic behavior in CXCR4-expressing colon cancer cells
}

\author{
HAN-NA SHIN, HYUN-HYE MOON and JA-LOK KU \\ Laboratory of Cell Biology, Cancer Research Institute, Seoul National University \\ College of Medicine, Seoul 110-799, Republic of Korea
}

Received June 30, 2012; Accepted August 27, 2012

DOI: $10.3892 / \mathrm{ijmm} .2012 .1141$

\begin{abstract}
Metastasis of cancer cells is a major cause of death in cancer patients. The process of cancer metastasis includes the proliferation of primary cancer cells, local invasion, intravasation and cancer cell survival in blood flow, extravasation and attachment to secondary organs and metastatic growth in a new environment. In these mechanisms of cancer metastasis, CXC chemokine receptor 4 (CXCR4) and its ligand play an important role. Stromal cell-derived factor-1 $\alpha$ (SDF-1 $\alpha$, also known as CXCL12) is well known as a ligand of CXCR4, and macrophage migration-inhibitory factor (MIF) has recently become known as a ligand of CXCR4. In many types of cancers including breast, pancreatic and colorectal cancer (CRC), CXCR4/SDF-1 $\alpha$ has been investigated in metastasis-related cancer behavior, which include cell proliferation, adhesion, migration and invasion. However, CXCR4/MIF has rarely been investigated in the metastatic behavior of colon cancer cells. In this report, the effect of SDF-1 $\alpha$ or MIF was studied on cell cycle, cell proliferation, adhesion and migration of the CXCR4-expressing colon cancer cell line SW480. SDF-1 $\alpha$ or MIF caused a decrease in the number of cells in G0/G1 phase and an increase in the numbers of cells in $\mathrm{S}$ and $\mathrm{G} 2 / \mathrm{M}$ phases. In addition, SDF-1 $\alpha$ or MIF caused an increase in cell proliferation, cell adhesion to fibronectin and migration. AMD3100, a CXCR4 antagonist, attenuated these effects, which included increased
\end{abstract}

Correspondence to: Professor Ja-Lok Ku, Laboratory of Cell Biology, Cancer Research Institute, Seoul National University College of Medicine, Seoul 110-799, Republic of Korea

E-mail: kujalok@snu.ac.kr

Abbreviations: CXCR4, CXC chemokine receptor 4; SDF-1 $\alpha$, stromal cell-derived factor-1 $\alpha$; CXCL12, CXC chemokine ligand 12; MIF, macrophage migration-inhibitory factor; ECM, extracellular matrix; CRC, colorectal cancer

Key words: CXC chemokine receptor 4, macrophage migrationinhibitory factor, stromal cell-derived factor- $1 \alpha$, colon cancer cells, metastasis cell proliferation, adhesion and migration due to treatment of CXCR4-expressing colon cancer cells with SDF-1 $\alpha$ or MIF. In conclusion, SDF-1 $\alpha$ or MIF affects the metastasis-related behaviors of CXCR4-expressing colon cancer cells.

\section{Introduction}

Colorectal cancer (CRC) is the third leading cause of cancer-related death for both genders throughout the world (1). Cancer cells can metastasize to distinct organs from the primary site (2). Moreover, metastasis of cancer cells is a major cause of death in cancer patients $(3,4)$. In particular, colon cancer cells mainly metastasize to the lymph nodes, liver, and lung (4,5). The processes and critical steps of metastasis include proliferation of primary cancer cells, local invasion, intravasation, cancer cell survival in blood flow, extravasation, attachment to secondary organs, and metastatic growth in a new environment (6). In this mechanism of metastasis for many types of cancer, chemokine receptors and their corresponding chemokine ligands play an important role (7).

One of the chemokine receptors that promotes metastasis is CXC chemokine receptor 4 (CXCR4) $(7,8)$. CXCR4 is a $\mathrm{G}$ protein-coupled human chemokine receptor, which has a seven-transmembrane domain. CXCR4 is mostly expressed in various cancer types including $\mathrm{CRC}$, breast cancer, prostate cancer, and ovarian cancer as well as immune cells including B lymphocytes and T lymphocytes (9). The expression of CXCR4 affects the metastatic behavior of CRC cells, which is associated with poor patient prognosis and lymphatic and distant dissemination (10-12). CXCR4-overexpressing cancer cells have an increased ability of migration in vitro and metastasis to other organs in vivo $(13,14)$. On the other hand, CXCR4-knockdown cancer cells have decreased invasive ability (15). CXCR4 modulates cellular biology (i.e., cell growth and migration) through several signaling pathways including $\mathrm{G}$ protein signaling, ERK, JNK, and JAK/STAT signaling by binding its ligand, CXC chemokine ligand 12 (CXCL12 also known as SDF-1 $\alpha$ ) $(16,17)$. Stromal cell-derived factor-1 $\alpha$ (SDF-1 $\alpha)$ is one of the small proinflammatory chemoattractant cytokines and binds to CXCR4 and CXCR7 $(18,19)$. SDF-1 $\alpha$ is expressed in primary tumors including breast cancer, pancreatic cancer, ovarian cancer 
and in primary sites of metastatic cancer (i.e., lung, liver, and bone) (18).

CXCR4/SDF-1 $\alpha$ influences a variety of behaviors in cancer cells, for example, migration, metastasis, growth/survival, angiogenesis, and malignant progression as well as trafficking of stem cells (19-21). In mechanisms of CXCR4/SDF-1 $\alpha$ mediated tumor metastasis, CXCR4-expressing cancer cells are attracted to a target organ that secretes SDF- $1 \alpha$ by sensing a chemokine gradient. Upon receiving this chemokine signal, CXCR4-expressing cancer cells migrate to the secondary organ through multiple processes $(6,7,18)$.

Recently, macrophage migration-inhibitory factor (MIF) has become known as a new ligand of CXCR4 and it has chemokine-like functions. Moreover, MIF binds to CXCR2, CXCR7, CD44, and CD74 (22). Inflammatory cells including $\mathrm{B}$ lymphocytes and $\mathrm{T}$ lymphocytes and various tumor cells have shown expression of MIF. MIF plays various roles as a critical mediator of acute and chronic inflammatory disease and is also involved in tumor progression and development (23). MIF regulates cell proliferation and survival in monocytes, $\mathrm{T}$ cells, and fibroblasts in an autocrine manner. Moreover, it regulates tumor cell proliferation and angiogenesis in a paracrine manner (24). In recent reports, it was shown that MIF regulates tumor cell metastasis in rhabdomyosarcoma and is associated with invasive ability of drug-resistant human colon cancer cells that express CXCR4 $(25,26)$.

Although the mechanism of CXCR4/SDF-1 $\alpha$-mediated metastasis-related cancer cell behaviors (i.e., invasion, cell proliferation and adhesion) is well known, the function of CXCR4/MIF in colon cancer metastasis remains largely unknown. To confirm the effect of SDF-1 $\alpha$ and to compare the effect of MIF with the effect of SDF-1 $\alpha$ in cancer metastatic behaviors, we performed experiments adding human recombinant SDF-1 $\alpha$ or MIF to CXCR4-expressing colon cancer cells. Here, we investigated the effect of SDF-1 $\alpha$ or MIF on cell cycle, proliferation, adhesion, and migration in CXCR4expressing colon cancer cells.

\section{Materials and methods}

CRC cell lines and culture conditions. Thirty-two human CRC cell lines were obtained from the Korean Cell Line Bank (Seoul, Korea) and were grown in RPMI-1640 medium with $10 \%$ fetal bovine serum (FBS), except for Caco-2 which was grown in Minimum Essential Medium with $10 \%$ FBS and WiDr in Dulbecco's modified Eagle's medium (all were from Invitrogen Life Technologies, Carlsbad, CA, USA) with $10 \% \mathrm{FBS}$. Each medium contained $100 \mathrm{U} / \mathrm{ml}$ of penicillin and $0.1 \mathrm{mg} / \mathrm{ml}$ of streptomycin. Cells were grown in humidified incubators at $37^{\circ} \mathrm{C}$, in $5 \% \mathrm{CO}_{2}$ and $95 \%$ air.

RNA isolation and cDNA synthesis. Cells were collected by trypsinization and suspended in easy-BLUE (Intron Biotechnology, Gyeonggi, Korea). According to the manufacturer's instructions, total RNA was isolated. For cDNA synthesis, $2 \mu \mathrm{g}$ of total RNA and $1 \mu \mathrm{l}$ of the random primers were mixed and heated at $70^{\circ} \mathrm{C}$ for $10 \mathrm{~min}$. Then, they were incubated on ice for $5 \mathrm{~min}$. A mixture containing $4 \mu \mathrm{l}$ of 5X FS buffer, $2 \mu 1$ of $0.1 \mathrm{M}$ DTT, $1 \mu \mathrm{l}$ of $2.5 \mathrm{mM}$ dNTP,
$1 \mu 1$ of Superscript II reverse transcriptase (Invitrogen Life Technologies) and $1 \mu \mathrm{l}$ of distilled water was added, and reverse transcription reaction was carried out. The reaction conditions were $1 \mathrm{~h}$ for $30 \mathrm{~min}$ at $42^{\circ} \mathrm{C}$ and $15 \mathrm{~min}$ at $80^{\circ} \mathrm{C}$. Finally, $80 \mu \mathrm{l}$ of distilled water was added to dilute the cDNA.

Reverse transcriptase-PCR (RT-PCR). Cells were collected by trypsinization and suspended in easy-BLUE. According to the manufacturer's instructions, total RNA was isolated and cDNA synthesis was performed. For PCR amplification, cDNAspecific primers for CXCR4, SDF- $1 \alpha$, MIF, and $\beta$-actin, as a quantitative control, were used. The primer sequences for CXCR2 were forward, 5'-AGGCACAGTGAAGACATCGG-3' and reverse, 5'-CAGCAGGCTCAGCAGGAATA-3' (27); for CXCR4 forward, 5'-AGGGGATCAGTATATACACTT-3' and reverse, 5'-TGCCCACAATGCCAGTTAAG-3' (28); for CXCR7 forward, 5'-TGGGTGGTCAGTCTCGT-3' and reverse, 5'-CCGGCAGTAGGTCTCAT-3' (29); for SDF-1 $\alpha$ forward, 5'-AGAGCCAACGTCAAGCATCT-3' and reverse, 5'-CGTCTTTGCCCTTTCATCTC-3' (30); for MIF forward, 5'-CTCTCCGAGCTCACCCAGCAG-3' and reverse, 5'-CGC GTTCATGTCGTAATAGTT-3' (31) and for $\beta$-actin forward, 5'-GACCACACCTTCTACAATGAG-3' and reverse, 5'-GCA TACCCCTCGTAGATGGG-3' (32). PCR amplification was carried out in a programmable thermal cycler (PCR System 9700; Applied Biosystems, Foster City, CA, USA). The amplified DNA fragments were fractionated in a $1.5 \%$ agarose gel and stained with ethidium bromide.

Protein isolation and western blotting. Cells were rinsed three times with PBS and lysed in PRO-PREP protein extraction solution (Intron Biotechnology) and placed on ice for $30 \mathrm{~min}$. The lysates were centrifuged at $13000 \mathrm{x}$ g for $20 \mathrm{~min}$ at $4^{\circ} \mathrm{C}$ and then the supernatant was collected. The protein concentration was determined using the SMART Micro BCA protein assay kit (Intron Biotechnology). Twelve micrograms of protein was resolved by $4 \mathrm{X}$ SDS sample buffer and boiled at $95^{\circ} \mathrm{C}$ for $5 \mathrm{~min}$. Protein was loaded on a $4-12 \%$ Bis-Tris gel at $100 \mathrm{~V}$ for $\sim 3 \mathrm{~h}$ and transferred to a polyvinylidene fluoride (PVDF) membrane (all were from Invitrogen Life Technologies) by electroblotting at $270 \mathrm{~mA}$ constant current for $1 \mathrm{~h} 30 \mathrm{~min}$ at $4^{\circ} \mathrm{C}$. For blocking, the membrane was incubated in $1.7 \%$ non-fat dry milk and $0.5 \%$ Tween 20-TBS buffer containing $1 \mathrm{mM}$ of $\mathrm{MgCl}_{2}$ for $1 \mathrm{~h}$ at room temperature. Primary antibodies against CXCR4 (Abcam, Cambridge, UK) (1:3,000), MIF (Santa Cruz Biotechnology, Inc., Santa Cruz, CA, USA) $(1: 1,000)$ and $\beta$-actin (Applied Biological Materials, Inc., Richmond, Canada) (1:5,000) were introduced to the membrane and incubated at room temperature for $1 \mathrm{~h}$. Peroxidase-conjugated mouse or rabbit $\mathrm{IgG}$ antibody (Jackson ImmunoReasearch, Baltimore, MD, USA) $(1: 5,000)$ was used as a secondary antibody and incubated at room temperature for $1 \mathrm{~h}$. Chemiluminescent working solution, WEST-ZOL (Intron Biotechnology), was decanted to the membrane. The membrane was exposed to Fuji RX film for 1-5 min.

Recombinant human proteins and AMD3100. Recombinant human proteins, rhSDF-1 $\alpha$ and rhMIF, were purchased from R\&D systems (Minneapolis, MN, USA) and $100 \mathrm{ng} / \mathrm{ml}$ of $\mathrm{SDF}-1 \alpha$ or $50 \mathrm{ng} / \mathrm{ml}$ of rhMIF was used in the proliferation 
assay, cell cycle analysis, cell counting, adhesion assay, and migration assay. AMD3100 (1 $\mu \mathrm{g} / \mathrm{ml})$ (Sigma-Aldrich, St. Louis, Mo, USA), which is a CXCR4 antagonist, was used for the inhibition of CXCR4.

Cell cycle analysis. For the cell cycle analysis, $4 \times 10^{5}$ cells/well were seeded on 6 -well plates. Cells were starved with serumfree media for $24 \mathrm{~h}$ and then $\mathrm{rhSDF}-1 \alpha(100 \mathrm{ng} / \mathrm{ml})$ or rhMIF (50 ng/ml) was added. After 12-72 h, cells were washed in cold PBS and collected by trypsinization. They were fixed in $70 \%$ ethanol and incubated at $-20^{\circ} \mathrm{C}$ for $48 \mathrm{~h}$. After fixation, cells were washed with cold PBS and stained with propidium iodide (PI) $(100 \mu \mathrm{g} / \mathrm{ml})$ (Sigma-Aldrich) and RNase A (10 mg/ml) (Intron Biotechnology) for $30 \mathrm{~min}$ in ice. Cells were introduced to a fluorescence-activated cell sorter (FACSCanto II; BD Biosciences, Franklin Lakes, NJ, USA) to determine the proportion of cell cycle phases.

Cell counting. Cells (3.6x10 $/$ well) were seeded on 6-well plates and incubated in growth medium for $24 \mathrm{~h}$. Cells were starved with serum-free media for $24 \mathrm{~h}$. For CXCR4 inhibition, the cells were pretreated with AMD3100 $(1 \mu \mathrm{g} / \mathrm{ml})$ for $2 \mathrm{~h}$ and then $\mathrm{rhSDF}-1 \alpha(100 \mathrm{ng} / \mathrm{ml})$ or $\mathrm{rhMIF}(50 \mathrm{ng} / \mathrm{ml})$ was added for $24-72 \mathrm{~h}$. The cells were stained with $0.4 \%$ Trypan blue and cell counting was performed using a Countess ${ }^{\circledR}$ cell counting chamber slide and Countess automated cell counter (Invitrogen Life Technologies). This experiment was repeated three times.

Adhesion assay. A 96-well plate was coated with $20 \mu \mathrm{g} / \mathrm{ml}$ of human fibronectin (Gibco-BRL) and incubated overnight at $4^{\circ} \mathrm{C}$. Before the adhesion assay, this plate was blocked in RPMI-1640 with $0.5 \%$ BSA for $1 \mathrm{~h}$. Cells were starved with serum-free media for $24 \mathrm{~h}$ and then $0.5 \times 10^{5}$ cells/well were added onto the fibronectin-coated plate with $\mathrm{rhSDF}-1 \alpha$ $(100 \mathrm{ng} / \mathrm{ml})$ or $\mathrm{rhMIF}(50 \mathrm{ng} / \mathrm{ml})$. In the case of CXCR4 inhibition, pretreatment with AMD3100 $(1 \mu \mathrm{g} / \mathrm{ml})$ for $30 \mathrm{~min}$ was carried out before seeding the cells. After $1 \mathrm{~h}$ of incubation at $37^{\circ} \mathrm{C}$, the adherent cells were washed in RPMI-1640 with $0.1 \%$ BSA, fixed with $96 \%$ ethanol and stained with $0.1 \%$ crystal violet. After washing with PBS, $0.2 \%$ Triton-X in distilled water was added to the wells. The absorbance was measured using an ELISA reader (Molecular Devices Co. Sunnyvale, CA, USA) at $595 \mathrm{~nm}$.

Migration assay. The migration assay was performed using a polycarbonate membrane Transwell plate with $8-\mu \mathrm{m}$ pore filters (24-well plate; Corning, Tewksbury, MA, USA). The inserts of the Transwell plate were rehydrated with warm RPMI-1640 at $37^{\circ} \mathrm{C}$ for $2 \mathrm{~h}$. Cells were starved with serumfree media for $24 \mathrm{~h}$ and $5 \times 10^{4}$ cells/well were placed on the insert in the serum-free media. In the case of CXCR4 inhibition, pretreatment with AMD3100 $(1 \mu \mathrm{g} / \mathrm{ml})$ for $30 \mathrm{~min}$ was carried out before placing the cells. In the lower well, rhSDF-1 $\alpha(100 \mathrm{ng} / \mathrm{ml})$ or $\mathrm{rhMIF}(50 \mathrm{ng} / \mathrm{ml})$ in RPMI-1640 was added, and the Transwell plate was incubated at $37^{\circ} \mathrm{C}$ for $48 \mathrm{~h}$. Cells on the upper surface of the insert were removed using a cotton swab. Migrated cells on the lower surface of the insert were washed in PBS three times and fixed with $100 \%$ ethanol and then stained with $0.1 \%$ crystal violet. The number of migrated cells was evaluted by photography and counted under an inverted microscope in three random fields. The migration assay was performed in triplicate wells.

Statistical analysis. All data were analyzed with the SPSS software version 19.0 and expressed as means \pm standard deviation. One-way analysis of variance (one-way ANOVA) was used to determine whether there were any significant changes in a time-dependent manner. For the post hoc test, Tukey was used. Comparisons between the two groups were carried out with the Student's two-tailed t-test. $\mathrm{P}<0.05$ was considered to indicate a statistically significant result.

\section{Results}

Expression of $C X C R 2, C X C R 4, C X C R 7, S D F-1 \alpha$, and $M I F$ in $C R C$ cell lines. In order to investigate the mRNA levels of CXCR2, CXCR4, CXCR7, MIF, and SDF-1 $\alpha$ in 32 human CRC cell lines, RT-PCR was carried out. The mRNA expression of CXCR2 was observed in several cell lines including SNU-503 and HCT116. The mRNA expression of CXCR4 in 10 cell lines including Caco- 2 and SW480 was highly detected. The mRNA expression of CXCR7 in 8 cell lines including Caco-2 and SNU-1047 was highly detected. The mRNA expression of MIF in most of the cell lines was moderately or highly detected. The mRNA expression of SDF-1 $\alpha$ was highly detected only in several cell lines including SNU-503 and Caco-2 (Fig. 1A). We performed western blotting to determine the CXCR4 and MIF protein expression in 17 CRC cell lines. The protein levels of CXCR4 and MIF were moderately or highly detected in most of the CRC cell lines (Fig. 1B).

SDF-1 $\alpha$ or MIF treatment and their effects on the cell cycle of CXCR4-expressing SW480 colon cancer cells. In order to investigate the effect of SDF-1 $\alpha$ or MIF on the cell cycle of CXCR4-expressing colon cancer cells, SW480 cells were treated with human recombinant SDF-1 $\alpha$ (100 ng/ml) or MIF (50 ng/ml). When SW480 cells were treated with SDF-1 $\alpha$, the percentage of cells in the G0/G1 phase decreased (from 70 to $43 \%$ ) and the percentage of cells in the $\mathrm{S}$ and $\mathrm{G} 2 / \mathrm{M}$ phases increased (from 16 to $29 \%$ and from 13 to $26 \%$, respectively) in a time-dependent manner $(\mathrm{P}<0.05$ in all phases) (Fig. 2A). Similarly, when SW480 cells were treated with MIF, the percentage of cells in the G0/G1 phase decreased (from 70 to $43 \%$ ) and the percentage of cells in the $\mathrm{S}$ and $\mathrm{G} 2 / \mathrm{M}$ phases increased (from 16 to $31 \%$ and from 13 to $23 \%$, respectively) in a time-dependent manner $(\mathrm{P}<0.05$ in all phases) (Fig. 2B).

SDF-1 $\alpha$ or MIF treatment and the effects on the cell proliferation of CXCR4-expressing SW480 colon cancer cells. In order to investigate the effect on cell viability of SDF-1 $\alpha$ or MIF in CXCR4-expressing colon cancer cells, we carried out cell proliferation assays. In serum-free media, SDF- $1 \alpha$ (100 ng/ml) or MIF (50 $\mathrm{ng} / \mathrm{ml})$ caused an increase in cell proliferation. When SW480 cells were treated with SDF-1 $\alpha$ or MIF, approximately a 1.8- and 2-fold increase in cell numbers was observed at 48 and $72 \mathrm{~h}$, respectively $(\mathrm{P}<0.05)$ (Fig. 3). When the cells were pretreated with AMD3100 (1 $\mu \mathrm{g} / \mathrm{ml})$ only, no effect on the viability of the two cell lines compared to the 

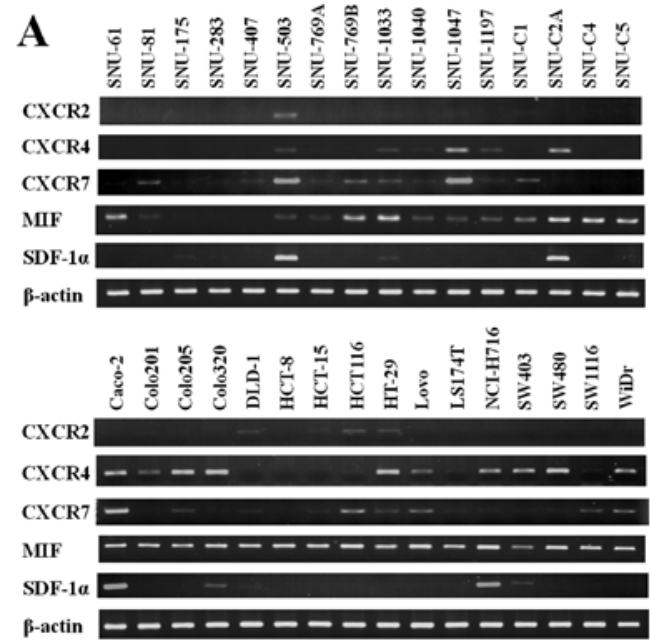
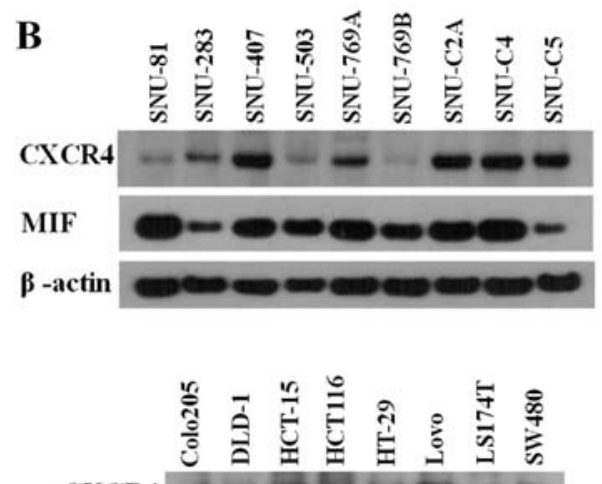

CXCR4 $=0+0$

MIF

$\beta$-actin

Figure 1. Analysis of CXCR2, CXCR4, CXCR7, MIF, and SDF-1 $\alpha$ expression levels by RT-PCR and western blotting. (A) The mRNA expression levels of CXCR2, CXCR4, CXCR7, MIF, and SDF-1 $\alpha$ in 32 human CRC cell lines were analyzed by RT-PCR. (B) The protein expression levels of CXCR4, MIF, and $\beta$-actin in 17 human CRC cell lines were analyzed by western blotting.
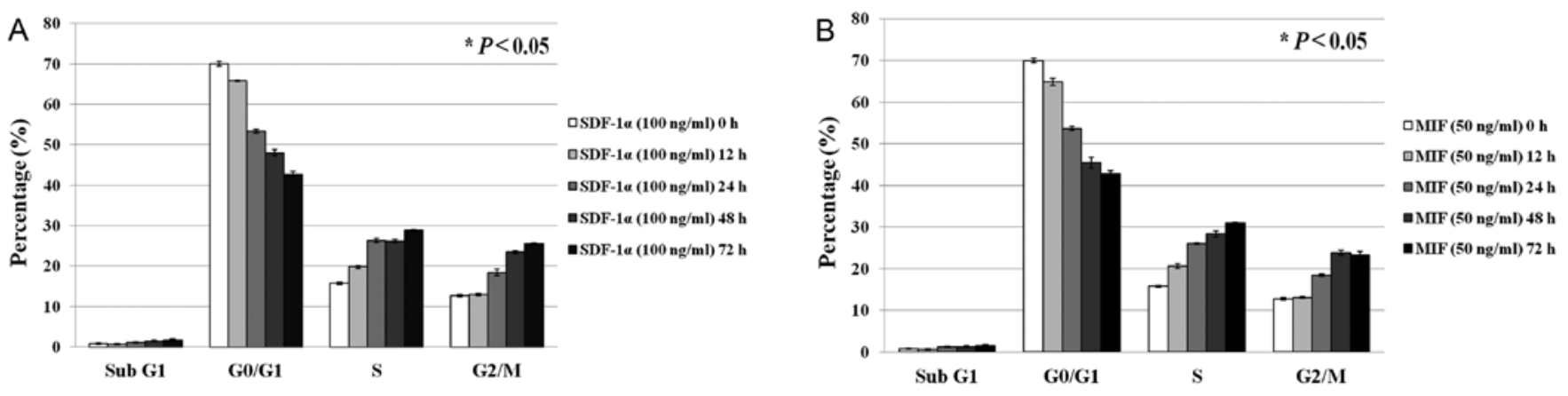

Figure 2. Effects of SDF-1 $\alpha$ or MIF on the cell cycle. Starved SW480 cells were treated separately using (A) SDF-1 $\alpha$ (100 ng/ml) or (B) MIF (50 ng/ml) in serum free media for 12-72 h. After ethanol fixation, cell cycle analysis was performed with PI staining and FACS. This experiment was repeated three times. "P-value, change of each phase in a time-dependent manner.

serum-free medium group was noted $(\mathrm{P}>0.05)$. Although SDF-1 $\alpha$ or MIF was added to SW480 cells, cell proliferation did not increase with AMD3100 pretreatment compared to the serum-free medium group $(\mathrm{P}>0.05)$.

SDF-1 $\alpha$ or MIF treatment and their effects on the adhesion to fibronectin in CXCR4-expressing SW480 colon cancer cells. We investigated the effects of SDF-1 $\alpha$ or MIF on adhesion to fibronectin, which is part of the extracellular matrix (ECM), in CXCR4-expressing colon cancer cells. Starved cells were seeded onto a fibronectin-coated 96-well plate with or without SDF-1 $\alpha(100 \mathrm{ng} / \mathrm{ml})$ and with or without MIF (50 ng/ml). In SW480 cells, SDF-1 $\alpha$ or MIF caused increased adhesion to fibronectin ( 22 and 30\%, respectively). Pretreatment with AMD3100 decreased these effects when MIF was added $(\mathrm{P}<0.05)$ (Fig. 4).

SDF-1 $\alpha$ or MIF treatment and their effects on the migratory ability of CXCR4-expressing SW480 colon cancer cells. The migratory ability of cancer cells is related to cancer metastasis. In order to determine the effect of SDF-1 $\alpha$ or MIF on the migration of CXCR4-expressing SW480 colon cancer cell line, we carried out a migration assay with Transwell plates. SDF-1 $\alpha(100 \mathrm{ng} / \mathrm{ml})$ and MIF $(50 \mathrm{ng} / \mathrm{ml})$ were applied separately to the lower wells and serum-free media were used as a negative control.

The migratory ability of the SW480 cells was enhanced $\sim 16-$ and 6 -fold by SDF- $1 \alpha$ and MIF, respectively $(\mathrm{P}<0.05)$. Only cells pretreated with AMD3100 $(1 \mu \mathrm{g} / \mathrm{ml})$ showed no significant effect. Moreover, pretreatment with AMD3100 attenuated the SDF-1 $\alpha$ - or MIF-induced increase in migration (Fig. 5).

\section{Discussion}

CXCR4 is G protein-coupled human chemokine receptor which has a seven-transmembrane domain. At first, CXCR4 was studied in the co-receptor of $\mathrm{T}$ and dendritic cells for HIV entry (33). Since then, CXCR 4 and its ligand, SDF- $1 \alpha$ have been studied in regards to many behaviors of cancer cells. CXCR4 mainly regulates cell migration, invasion, cell growth/survival, malignant progression, and angiogenesis by binding its ligand, SDF- $1 \alpha$, in many cancer cells including ovarian cancer, breast cancer, and rhabdomyosarcoma $(7,34)$. In 2007, Bernhagen et al (22) showed that MIF interacts with CXCR2 and CXCR4 in Jurkat T cells. CXCR4/MIF has 

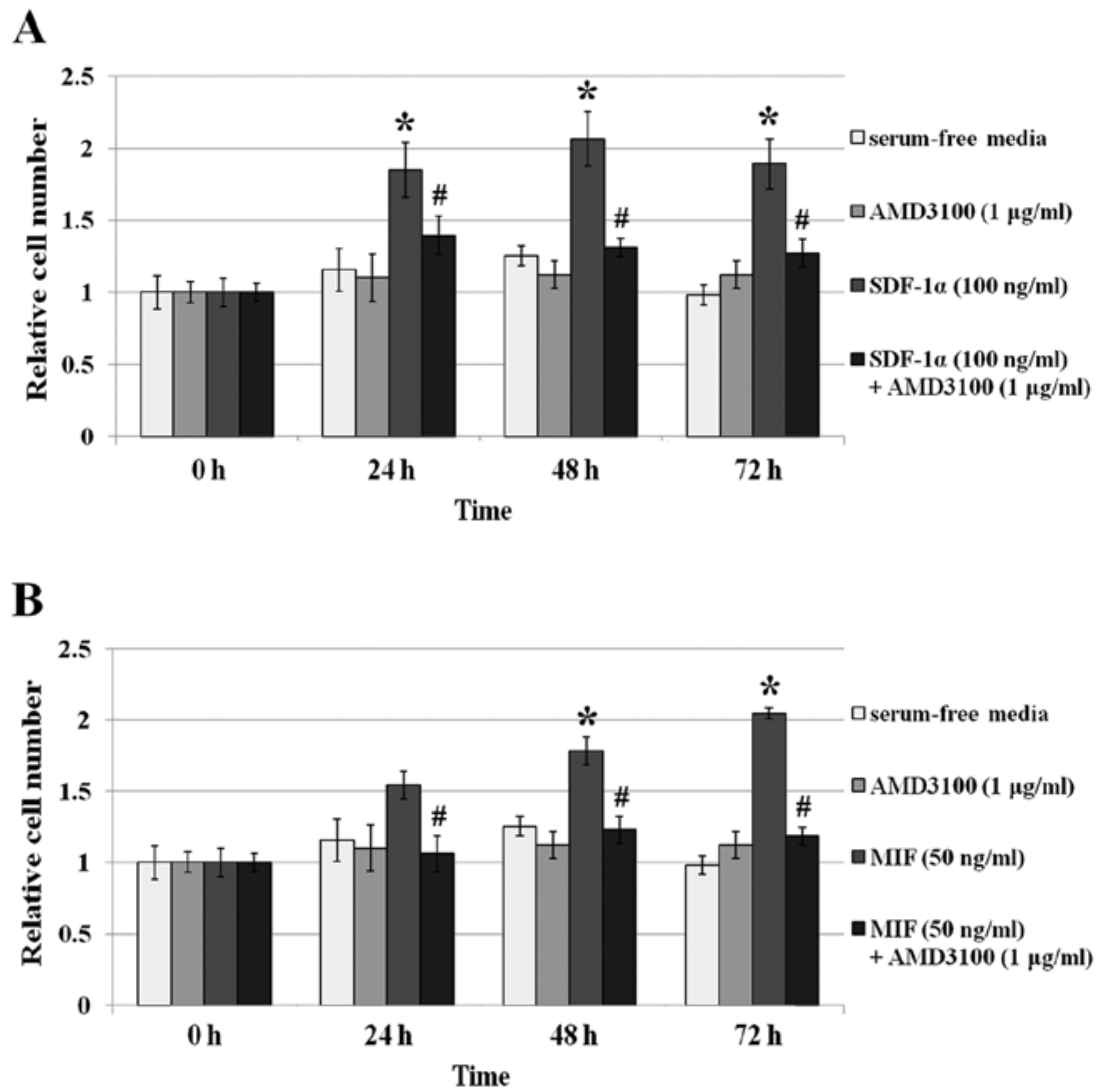

Figure 3. Effects of SDF-1 $\alpha$ or MIF on cell proliferation. A proliferation assay in SW480 cells was carried out using cell counting in triplicate wells. For CXCR4 blocking, $1 \mu \mathrm{g} / \mathrm{ml}$ of AMD3100 was used to pretreat the cells for $2 \mathrm{~h}$. SW480 cells were treated with (A) SDF-1 $\alpha$ (100 ng/ml) or (B) MIF (50 ng/ml) for 24-72 $\mathrm{h}$. ${ }^{\mathrm{P}}<0.05$ compared with serum-free medium group; ${ }^{*} \mathrm{P}<0.05$ compared with SDF-1 $\alpha$ or MIF group.

A

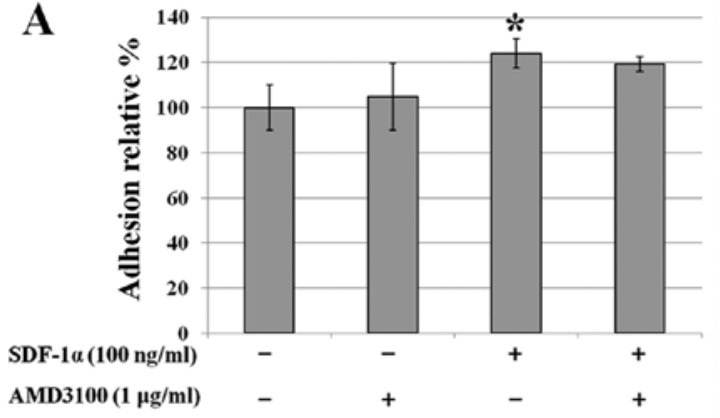

B

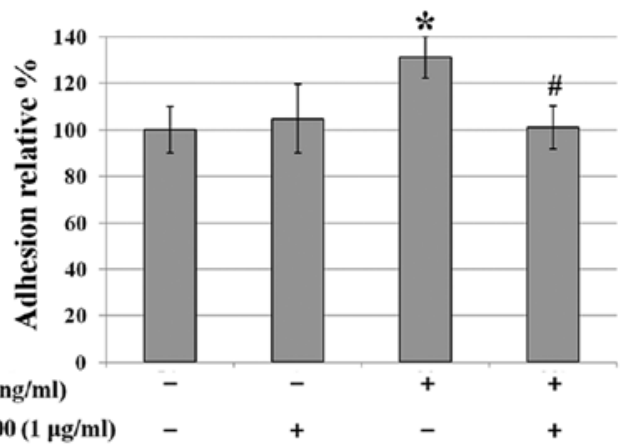

Figure 4. Effects of SDF-1 $\alpha$ or MIF on the cell adhesion to fibronectin. An adhesion assay in SW480 cells was carried out with fibronectin (20 $\mu \mathrm{g} / \mathrm{ml})$-coated 96-well plates. SW480 cells were seeded on plates (A) with or without SDF-1 $\alpha$ (100 ng/ml) and (B) with or without MIF (50 ng/ml). For inhibition of CXCR4, cells were pretreated with AMD3100 $(1 \mu \mathrm{g} / \mathrm{ml})$. This experiment was repeated three times. ${ }^{*} \mathrm{P}<0.05$ compared with serum-free medium group; ${ }^{\#} \mathrm{P}<0.05$ compared with SDF-1 $\alpha$ or MIF group.

been studied in drug-resistant human colon cancer cells and CXCR4/MIF-mediated JNK and AKT signaling pathways in mouse fibroblasts and T cells $(25,35)$. AMD3100 is a prototype non-peptide antagonist of CXCR4. AMD3100 binds to CXCR4 through the interactions of three acidic anchor-point residues in CXCR4 and blocks other agonists from binding to CXCR4 (36).

Behavior of metastatic cancer cells are related to cell survival, resistance to apoptosis, adhesion to extracellular matrix molecules, and cell migration/invasion. The function of $\mathrm{CXCR} 4 / \mathrm{SDF}-1 \alpha$ in these metastatic features has been intensely studied in many types of cancer cells $(11,37)$. However, CXCR4/MIF has rarely been studied particularly in colon cancer cells. In this study, we hypothesized that SDF-1 $\alpha$ or MIF, which interacts with CXCR4, affects the metastatic behaviors of CXCR4-expressing colon cancer cells and performed experiments to confirm the effects of SDF- $1 \alpha$ or MIF on CXCR4-expressing colon cancer cells.

Many cancer cells including breast, ovarian, and prostate cancer overexpress CXCR4 (9). We also found that the mRNA or protein of CXCR4 was expressed in 17 out of $32(53 \%)$ and 17 out of $17(100 \%)$ CRC cell lines, respectively. CXCR2 and 


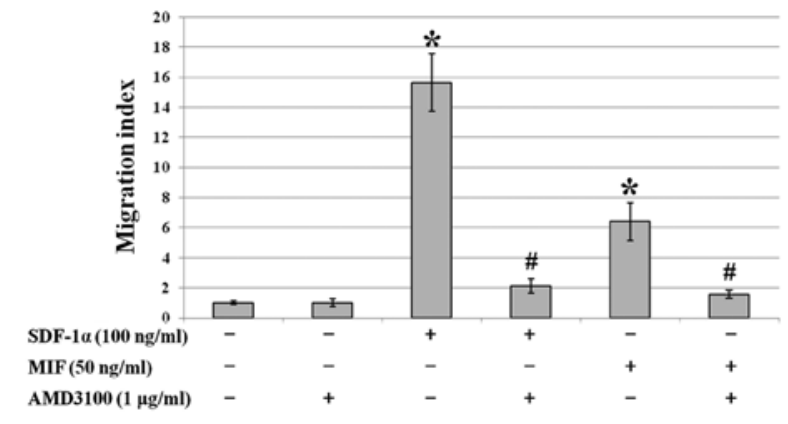

Figure 5. Effects of SDF-1 $\alpha$ or MIF on migratory ability. A migration assay in SW480 cells was carried out with Transwell plates in triplicate wells. Each lower well was filled with SDF-1 $\alpha(100 \mathrm{ng} / \mathrm{ml})$ or MIF $(50 \mathrm{ng} / \mathrm{ml})$ in serumfree medium. The cells were treated with AMD3100 $(1 \mu \mathrm{g} / \mathrm{ml})$ for blockage of CXCR4. This experiment was repeated three times. " $\mathrm{P}<0.05$ compared with serum-free medium group; ${ }^{~} \mathrm{P}<0.05$ compared with SDF-1 $\alpha$ or MIF group.

CXCR7 are also receptors for SDF-1 $\alpha$ and MIF $(19,22,26)$. Therefore, we confirmed their mRNA level by performing RT-PCR. We used SW480 cells, which do not express mRNA of CXCR2 and CXCR7, in order to confirm the effect of MIF or SDF-1 $\alpha$ on CXCR4-expressing colon cancer cells. MIF is induced in the serum and tumor specimens of patients with $\mathrm{CRC}$ and it is overexpressed in solid tumors including prostate and breast cancer $(38,39)$. We observed that the mRNA or protein of MIF was expressed in 29 out of $32(90 \%)$ and 17 out of 17 (100\%) CRC cell lines, respectively. The SDF-1 $\alpha$ expression has been frequently noted in primary tumors and at the sites of metastasis, which include lymph nodes, bone marrow, liver, and lung (40). In this study, the mRNA expression of SDF-1 $\alpha$ was rarely observed in 9 out of $32(28 \%)$ CRC cell lines except in SNU-503, SNU-C2A, Caco-2 and NCI-H716.

Cell proliferation/survival is an important part of the mechanism of cancer metastasis. The transition of the cell cycle phase is related to cell division and proliferation/survival (41). In peripheral blood CD34 ${ }^{+}$cells, SDF- $1 \alpha$ significantly increased the percentage of cells in $\mathrm{S}$ and $\mathrm{G} 2 / \mathrm{M}$ phases (42). In addition, SDF- $1 \alpha$ decreased cells in the sub-G1 phase and increased cell proliferation in serum-free conditions in CXCR4-expressing pancreatic cancer cells (43). The effect of MIF on cell cycle in colon cancer cells has been rarely studied. Therefore, we investigated the effects of SDF-1 $\alpha$ or MIF on cell cycle and cell proliferation. In general, cells incubated in serum-free media are arrested in the cell cycle at the G0/G1 phase. In this report, SW480 cells were starved with serum-free media and the result at the $0 \mathrm{~h}$, the start point, showed a high percentage of cells in the G0/G1 phase. The percentage of SW480 cells in S and G2/M phases increased in a time-dependent manner after the cells were treated separately with SDF-1 $\alpha$ or MIF.

In CXCR4-expressing pancreatic cancer cells, the cell proliferation was enhanced by the addition of SDF-1 $\alpha$ in serum-free conditions (43). MIF activates AKT signaling, which is related to cell survival and induces the suppression of apoptosis in fibroblasts and breast cancer cells (44). In this study, treatment with SDF-1 $\alpha$ or MIF showed an increase in cell proliferation by carrying out cell counting. When CXCR4 was blocked by AMD3100, the effect of the increased cell proliferation by SDF-1 $\alpha$ or MIF was inhibited.

Colon cancer cells can disseminate to the liver and lymph nodes through lymphatic vessels or blood vessels. In these processes, colon cancer cells are detached from the primary site and invade lymphatic vessels or blood vessels and migrate to secondary sites (6). When colon cancer cells are metastasized, they attach to various ECM molecules (i.e., E-selectin, integrin, and fibronectin) (6). CXCR4/SDF-1 $\alpha$ was found to increase cell adhesion to elements of the ECM including fibronectin and collagen type IV by activating the ERK signaling pathway in ovarian cancer cells (45). However, the effect of SDF-1 $\alpha$ or MIF on CXCR4-expressing colon cancer cell adhesion has rarely been reported. From the results of the adhesion assay in this study, SDF-1 $\alpha$ or MIF induced an increase (approximately 22-30\%) in cell adhesion to fibronectin in SW480 cells. Blockage of CXCR4 by AMD3100 did not inhibit the effect of SDF-1 $\alpha$ on cell adhesion to fibronectin but decreased the effect of MIF. Further experiments are necessary to confirm the effect of SDF-1 $\alpha$ or MIF on cell adhesion to other ECM molecules (i.e., laminin, Matrigel, and collagen) in CXCR4-expressing colon cancer cells.

As previously reported, migration/invasion of cancer cells is related to metastasis, and chemokine receptors and their ligands are involved in the mechanisms of metastasis (7). CXCR4/SDF-1 $\alpha$ regulates cell trafficking, migration, and invasion in stem cells and many cancer types including breast and prostate cancer $(18,21)$. CXCR4/MIF was found to promote the invasive ability of drug-resistant colon carcinoma HT-29 cells in an autocrine manner. When CXCR4 or MIF was blocked by its inhibitor (each AMD3100 and ISO-1), the aggressive phenotype of drug-resistant HT-29 cells was abolished (25). We observed that SDF-1 $\alpha$ or MIF caused an increase in cell migration in the CXCR4-expressing colon cancer cell line, SW480. When the cells were pretreated with AMD3100, the effect of increased migration by SDF-1 $\alpha$ or MIF was blocked.

Based on the finding of this study, we conclude that not only the CXCR4/SDF-1 $\alpha$ axis but also the CXCR4/MIF axis induces metastatic behavior of colon cancer cells and thus can be a therapeutic target in the metastasis of colon cancer cells. Moreover, further studies concerning signaling pathways and other metastatic features are required.

\section{Acknowledgements}

This study was supported by the Mid-Career Researcher Program (MEST R01-2008-000-20108-0) and the Priority Research Centers Program (2009-0093820) through the National Research Foundation of Korea Grant funded by the MEST.

\section{References}

1. Ferlay J, Shin HR, Bray F, Forman D, Mathers C and Parkin DM: Estimates of worldwide burden of cancer in 2008: GLOBOCAN 2008. Int J Cancer 127: 2893-2917, 2010.

2. Gupta GP and Massague J: Cancer metastasis: building a framework. Cell 127: 679-695, 2006.

3. August DA, Ottow RT and Sugarbaker PH: Clinical perspective of human colorectal cancer metastasis. Cancer Metastasis Rev 3: 303-324, 1984. 
4. Headrick JR, Miller DL, Nagorney DM, et al: Surgical treatment of hepatic and pulmonary metastases from colon cancer. Ann Thorac Surg 71: 975-980, 2001.

5. Welter S, Jacobs J, Krbek T, Poettgen C and Stamatis G: Prognostic impact of lymph node involvement in pulmonary metastases from colorectal cancer. Eur J Cardiothorac Surg 31: $167-172,2007$.

6. Gout S and Huot J: Role of cancer microenvironment in metastasis: focus on colon cancer. Cancer Microenviron 1: 69-83, 2008

7. Kakinuma T and Hwang ST: Chemokines, chemokine receptors, and cancer metastasis. J Leukoc Biol 79: 639-651, 2006.

8. O'Hayre M, Salanga C, Handel T and Allen S: Chemokines and cancer: migration, intracellular signalling and intercellular communication in the microenvironment. Biochem $\mathbf{J} 409$ : 635-649, 2008.

9. Balkwill F: Cancer and the chemokine network. Nat Rev Cancer 4: 540-550, 2004.

10. Kim J, Takeuchi H, Lam ST, et al: Chemokine receptor CXCR4 expression in colorectal cancer patients increases the risk for recurrence and for poor survival. J Clin Oncol 23: 2744-2753, 2005.

11. Schimanski CC, Schwald S, Simiantonaki N, et al: Effect of chemokine receptors CXCR4 and CCR7 on the metastatic behavior of human colorectal cancer. Clin Cancer Res 11: 1743-1750, 2005.

12. Yoshitake N, Fukui H, Yamagishi $\mathrm{H}$, et al: Expression of SDF-1 $\alpha$ and nuclear CXCR4 predicts lymph node metastasis in colorectal cancer. Br J Cancer 98: 1682-1689, 2008.

13. Luker KE and Luker GD: Functions of CXCL12 and CXCR4 in breast cancer. Cancer Lett 238: 30-41, 2006.

14. Kang Y, Siegel PM, Shu W, et al: A multigenic program mediating breast cancer metastasis to bone. Cancer cell 3 . 537-549, 2003.

15. Smith MCP, Luker KE, Garbow JR, et al: CXCR4 regulates growth of both primary and metastatic breast cancer. Cancer Res 64: 8604-8612, 2004.

16. Zheng H, Fu G, Dai T and Huang H: Migration of endothelial progenitor cells mediated by stromal cell-derived factor-1alpha/CXCR4 via PI3K/Akt/eNOS signal transduction pathway. J Cardiovasc Pharmacol 50: 274-280, 2007.

17. Busillo JM and Benovic JL: Regulation of CXCR4 signaling. Biochim Biophys Acta 1768: 952-963, 2007.

18. Wang J, Loberg R and Taichman RS: The pivotal role of CXCL12 (SDF-1)/CXCR4 axis in bone metastasis. Cancer Metastasis Rev 25: 573-587, 2006.

19. Sun X, Cheng G, Hao M, et al: CXCL12/CXCR4/CXCR7 chemokine axis and cancer progression. Cancer Metastasis Rev 29: 709-722, 2010

20. Liekens S, Schols D and Hatse S: CXCL12-CXCR4 axis in angiogenesis, metastasis and stem cell mobilization. Curr Pharm Des 16: 3903-3920, 2010.

21. Kucia M, Reca R, Miekus K, et al: Trafficking of normal stem cells and metastasis of cancer stem cells involve similar mechanisms: pivotal role of the SDF 1-CXCR4 axis. Stem Cells 23: 879-894, 2005

22. Bernhagen J, Krohn R, Lue H, et al: MIF is a noncognate ligand of CXC chemokine receptors in inflammatory and atherogenic cell recruitment. Nat Med 13: 587-596, 2007.

23. Bach JP, Rinn B, Meyer B, Dodel R and Bacher M: Role of MIF in inflammation and tumorigenesis. Oncology 75: 127-133, 2008

24. Mitchell RA and Bucala R: Tumor growth-promoting properties of macrophage migration inhibitory factor (MIF). Semin Cancer Biol 10: 359-366, 2000.

25. Dessein AF, Stechly L, Jonckheere N, et al: Autocrine induction of invasive and metastatic phenotypes by the MIF-CXCR4 axis in drug-resistant human colon cancer cells. Cancer Res 70: 4644-4654, 2010.
26. Tarnowski M, Grymula K, Liu R, et al: Human rhabdomyosarcomas secrete MIF that modulates metastatic behavior of tumor cells and inhibits recruitment of cancer-associated fibroblasts. Mol Cancer Res 8: 1328-1343, 2010.

27. Liu Z, Yang L, Xu J, Zhang X and Wang B: Enhanced expression and clinical significance of chemokine receptor CXCR2 in hepatocellular carcinoma. J Surg Res 166: 241-246, 2011.

28. Salim JP, Goette NP, Lev PR, et al: Dysregulation of stromal derived factor $1 / \mathrm{CXCR} 4$ axis in the megakaryocytic lineage in essential thrombocythemia. Br J Haematol 144: 69-77, 2009.

29. Zheng K, Li HY, Su XL, et al: Chemokine receptor CXCR7 regulates the invasion, angiogenesis and tumor growth of human hepatocellular carcinoma cells. J Exp Clin Cancer Res 29: 31, 2010.

30. Brand S, Dambacher J, Beigel F, et al: CXCR4 and CXCL12 are inversely expressed in colorectal cancer cells and modulate cancer cell migration, invasion and MMP-9 activation. Exp Cell Res 310: 117-130, 2005.

31. Wada S, Fujimoto S, Mizue Y and Nishihira J: Macrophage migration inhibitory factor in the human ovary: presence in the follicular fluids and production by granulosa cells. Biochem Mol Biol Int 41: 805-814, 1997.

32. Hemmati HD, Nakano I, Lazareff JA, et al: Cancerous stem cells can arise from pediatric brain tumors. Proc Natl Acad Sci USA 100: 15178-15183, 2003.

33. Granelli-Piperno A, Moser B, Pope M, et al: Efficient interaction of HIV-1 with purified dendritic cells via multiple chemokine coreceptors. J Exp Med 184: 2433-2438, 1996.

34. Balkwill F: The significance of cancer cell expression of the chemokine receptor CXCR4. Semin Cancer Biol 14: 171-179, 2004.

35. Lue H, Dewor M, Leng L, Bucala R and Bernhagen J: Activation of the JNK signalling pathway by macrophage migration inhibitory factor (MIF) and dependence on CXCR4 and CD74. Cell Signal 23: 135-144, 2011.

36. Rosenkilde MM, Gerlach LO, Jakobsen JS, Skerlj RT, Bridger GJ and Schwartz TW: Molecular mechanism of AMD3100 antagonism in the CXCR4 receptor. J Biol Chem 279: 3033-3041, 2004.

37. Kucia M, Jankowski K, Reca R, et al: CXCR4-SDF-1 signalling, locomotion, chemotaxis and adhesion. J Mol Histol 35: 233-245, 2004.

38. Takahashi N, Nishihira J, Sato Y, et al: Involvement of macrophage migration inhibitory factor (MIF) in the mechanism of tumor cell growth. Mol Med 4: 707-714, 1998.

39. He XX, Chen K, Yang J, et al: Macrophage migration inhibitory factor promotes colorectal cancer. Mol Med 15: 1-10, 2009

40. Chambers AF, Groom AC and MacDonald IC: Dissemination and growth of cancer cells in metastatic sites. Nat Rev Cancer 2: 563-572, 2002

41. Schwartz GK and Shah MA: Targeting the cell cycle: a new approach to cancer therapy. J Clin Oncol 23: 9408-9421, 2005.

42. Lataillade JJ, Clay D, Dupuy C, et al: Chemokine SDF-1 enhances circulating CD34(+) cell proliferation in synergy with cytokines: possible role in progenitor survival. Blood 95: 756-768, 2000

43. Marchesi F, Monti P, Leone BE, et al: Increased survival, proliferation, and migration in metastatic human pancreatic tumor cells expressing functional CXCR4. Cancer Res 64: 8420-8427, 2004.

44. Lue H, Thiele M, Franz J, et al: Macrophage migration inhibitory factor (MIF) promotes cell survival by activation of the Akt pathway and role for CSN5/JAB1 in the control of autocrine MIF activity. Oncogene 26: 5046-5059, 2007.

45. Shen X, Wang S, Wang H, Liang M, Xiao L and Wang Z: The role of SDF-1/CXCR4 axis in ovarian cancer metastasis. J Huazhong Univ Sci Technolog Med Sci 29: 363-367, 2009. 